\title{
SENTIMENTO CONSTITUCIONAL, \\ PATRIOTISMO CONSTITUCIONAL E \\ CONSTITUCIONALISMO POPULAR: \\ POSSIBILIDADES PARA NOSSO PAÍS?
}

\section{CONSTITUTIONAL SENTIMENT, CONSTITUTIONAL PATRIOTISM AND POPULAR CONSTITUTIONALISM: POSSIBILITIES FOR OUR COUNTRY?

SENTIMIENTO CONSTITUCIONAL, PATRIOTISMO CONSTITUCIONAL Y
CONSTITUCIONALISMO POPULAR: ¿POSIBILIDADES PARA NUESTRO PAÍS?

Licença CC BY:

Artigo distribuído sob os termos Creative Commons, permite uso e distribuição irrestrita em qualquer meio desde que o autor credite a fonte original.

\section{Vitor Gonçalves Machado'}

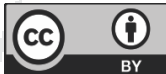

\section{Daury Cesar Fabriz²}

Resumo: Os fenômenos do sentimento constitucional, patriotismo constitucional e constitucionalismo popular, presentes nos estudos de Teoria da Constituição, são importantes para refletirmos acerca de sua aplicação à realidade jurídicoconstitucional brasileira. Assim, precipuamente a partir do método dedutivo, pretende-se analisar, mesmo que de forma não exaustiva, tais movimentos, com o objetivo de verificar a aplicabilidade dos mesmos em nosso país rumo à construção de um sentimento próprio de Constituição. Ao final, pretende-se dar início a uma "teoria da educação constitucional" com o fim de, a médio e longo prazo, florescer em solo brasileiro o sentimento constitucional.

Palavras-chave: Sentimento constitucional; Patriotismo constitucional; Constitucionalismo popular; Educação constitucional.

Abstract: The phenomena of constitutional sentiment, constitutional patriotism and popular constitutionalism, present in the studies of Constitutional Theory, are important for reflecting on its application to the Brazilian legal-constitutional reality. Using the deductive method, this work analyzes these movements, though not exhaustively, in order to determine their applicability in Brazil, aiming for the construction of a proper constitutional sentiment. The ultimate aim of this work is to

1 Doutorando em Direitos e Garantias Fundamentais (Faculdade de Direito de Vitória - FDV, Vitória/ES, Brasil). Mestre em Direito Processual (Universidade Federal do Espírito Santo - UFES). Integrante do Grupo de Pesquisa "Hermenêutica Jurídica e Jurisdição Constitucional" (FDV). Advogado. E-mail: vitor.g.machado@hotmail.com.

2 Doutor e Mestre em Direito (UFMG - Universidade Federal de Minas Gerais). Presidente da Academia Brasileira de Direitos Humanos (ABDH). Professor da Pós-Graduação em Direito da FDV, Vitória/ES, Brasil. Professor do Curso de Graduação em Direito da UFES. Professor coordenador do Grupo de Pesquisa "Estado, Democracia Constitucional e Direitos Fundamentais". (FDV). Advogado. E-mail: daury@terra.com.br. 
begin a "theory of constitutional education" that will promote a constitutional sentiment in Brazil in the medium and long terms.

Keywords: Constitutional sentiment; Constitutional patriotism; Popular constitutionalism; Constitutional education.

Resumen: Los fenómenos del sentimiento constitucional, patriotismo constitucional y constitucionalismo popular, presentes en los estudios de Teoría de la Constitución, son importantes para reflexionar acerca de su aplicación a la realidad jurídico-constitucional brasileña. Así, principalmente a partir del método deductivo, se pretende analizar, mismo que de forma no exaustiva, tales movimientos, con el objetivo de verificar la aplicabilidad de los mismos en nuestro país rumbo a la construcción de un sentimiento propio de Constitución. Al final, se pretende dar inicio a una "teoría de la educación constitucional" con el fin de, a medio y largo plazo, florecer en suelo brasileño el sentimiento constitucional.

Palabras clave:Sentimiento constitucional; Patriotismo constitucional; Constitucionalismo popular; Educación constitucional.

\section{INTRODUÇÃO}

A Teoria da Constituição representa uma disciplina dentro dos Cursos de Direito normalmente anterior ao estudo do Direito Constitucional. A importância daquela é sentida quando passamos a vivenciar justamente o contrário: uma falta de maiores análises sobre conceitos e fenômenos advindos de obras de autores estudados dentro da Teoria da Constituição - não somente a teoria clássica, mas também aquelas que desafiam dogmas e buscam superar paradigmas constitucionais.

Nesse sentido, revela-se importante elucidar neste ensaio três conceitos/fenômenos que foram elaborados por autores estrangeiros e que, em certa medida, podem (ou não) serem aplicados, ou ao menos refletidos, para nossa experiência nacional, aquilo que podemos chamar de "teoria constitucional brasileira" ou "constitucionalismo brasileiro" (se é que eles existem), ou, também ao menos, caminhar em rumo de uma possível construção de um sentimento próprio de Constituição.

Os conceitos/fenômenos que serão doravante refletidos foram elaborados por autores estrangeiros, oriundos de países da Europa e dos Estados Unidos da América (EUA). A primeira pergunta que surge, portanto, não deixa de ser outra: as realidades dos países (Brasil em contraposição aos países europeus/EUA) são as mesmas, ou são diferentes? Podemos pensar na aplicação de conceitos importados para a realidade jurídica, econômica e social brasileira?

Com esse foco, e deixando ao final a análise sobre a (im)possibilidade de aplicação dos fenômenos a serem apresentados neste artigo, abordaremos os conceitos de "sentimento constitucional", elaborada por Pablo Lucas Verdú; "patriotismo constitucional", tratada mais enfaticamente por Jürgen Habermas; e, por fim, "constitucionalismo popular", fenômeno histórico trazido à tona, entre outros, por Larry Kramer e Mark Tushnet. Os capítulos 1, 2 e 3, respectivamente, serão próprios para 
apresentar elucubrações sobre esses conceitos. A metodologia a ser empregada, diante do objeto de estudo deste ensaio, será precipuamente através do método dedutivo, partindo-se de premissas gerais (pensamentos de autores da Teoria do Direito, Filosofia do Direito, Direito Constitucional e Teoria da Constituição) para um pensamento particular, que será a ideia a ser refletida a partir do capítulo 4. Também será utilizada pesquisa de tipo bibliográfica, com predominância de autores que discorrem sobre "sentimento constitucional", "patriotismo constitucional" e "constitucionalismo popular", além de doutrina, em menor escala, que disserta sobre educação constitucional e os problemas da educação em particular.

Dessa forma, nos capítulos 4 e seguintes, faremos uma incursão acerca de uma proposta de "teoria da educação constitucional", o que será apresentada após a concentração de nossa atenção em pontos cruciais para pensarmos sobre uma possibilidade (ou não) de aplicação dos fenômenos abordados, justificando nossas compreensões.

Assim, é o constitucionalismo o ponto principal neste estudo, um movimento histórico, político, social e jurídico que surgiu fortemente a partir de três principais paradigmas (inglês, norte-americano e francês), que traz como centro da regulamentação das relações sociais e das decisões políticas a figura de uma Constituição.

\section{SENTIMENTO CONSTITUCIONAL}

Pablo Lucas Verdú, professor espanhol de Direito Constitucional, vivenciou de perto o regime totalitário imposto pelo militar Francisco Franco, entre o final da década de 1930 e meados da década de 1970 do século XX. Conforme prólogo escrito por Agassiz Almeida Filho, Verdú, nascido em Salamanca, em 1923, presenciou uma Espanha mergulhada pelo regime político ditatorial denominado "franquismo". Uma Espanha que enfrentou uma época (décadas 1930-1970) em que não havia em solo espanhol uma Lei Fundamental para chamar de Constituição³.

A Constituição espanhola entrou em vigor em 29 de dezembro de 1978, contendo um total de 169 artigos, sem mencionar as normas positivadas em suas disposições adicionais e disposições transitórias ${ }^{4}$. Foi justamente alguns anos depois, em 1985, que Verdú publicou sua obra "El sentimiento constitucional: aproximación al estudio del sentir constitucional como modo de integración política", onde estabeleceu o conceito de sentimento constitucional após analisar o fenômeno do sentimento jurídico 5 .

3 ALMEIDA FILHO, Agassiz. Prólogo. In: VERDÚ, Pablo Lucas. O sentimento constitucional: aproximação ao estudo do sentir constitucional como modelo de integração política. Tradução e prefácio de Agassiz Almeida Filho. Rio de Janeiro: Forense, 2004.

4 A Constituição da Espanha em seu original pode ser conferida no sítio eletrônico: <https://www.boe.es/legislacion/ documentos/ConstitucionCASTELLANO.pdf>. Acesso em: 13 set. 2018.

5 VERDÚ, Pablo Lucas. O sentimento constitucional: aproximação ao estudo do sentir constitucional como modelo de integração política. Tradução e prefácio de Agassiz Almeida Filho. Rio de Janeiro: Forense, 2004, p. 5. 
Para Verdú, sentir significa estar implicado em algo; significa não um mero acompanhamento, mas sim fazer parte estrutural do pensamento e da ação ${ }^{6}$. Nesse sentido, o sentimento jurídico é a adesão emocional que brota da convicção de que determinadas normas, escritas ou consuetudinárias, são justas e boas para a convivência7. É, além disso, "implicar-se com o Direito vigente, com o todo ou com parte dele, dando-lhe apoio"8.

Sentimento constitucional, a seu turno, consistiria na "adesão interna às normas e instituições fundamentais de um país, experimentada com intensidade mais ou menos consciente", pois "estimase (...) que são boas e convenientes para a integração, manutenção e desenvolvimento de uma justa convivência"9. O autor pontua que esse afeto às normas fundamentais não necessita de um exato conhecimento de suas peculiaridades e funcionamento. Porém, no sentimento constitucional, o grande destaque é a existência de um grau de aceitação e adesão a tais normas, sendo um sentimento espontâneo, público e representativo ${ }^{10}$. Não se trata, portanto, de uma criação legislativa, ou uma imposição legal à sociedade. "Trata-se de uma sensação espontânea que surge no seio social de acordo com a confiabilidade dos cidadãos na Constituição e em seu efetivo cumprimento"11, como explica Ivy de Souza Abreu ao analisar a ideia de Lucas Verdú.

O afeto mais ou menos intenso pela ordem fundamental em busca de uma justa convivência é o ponto cerne do sentimento constitucional. Tanto é que o próprio autor identifica o fenômeno como pertencente à Psicologia Social'12, alheio a uma teoria mais estrita da Constituição. Afeto e adesão às normas e instituições fundamentais são palavras-chave nesse fenômeno.

Sendo assim, o papel que cabe ao sentimento constitucional é muito importante. Além de buscar construir no âmago da sociedade um valor afetivo pela Constituição, em conjunto com a adesão interna às normas e instituições fundamentais do Estado (tendo antes em conta o direito do que a lei escrita), almeja-se também reduzir a distância entre o ordenamento jurídico vigente e o seu contato com a realidade. Ou seja, deseja-se a existência de ordenamento vivo, um ordenamento sentido, aquele próprio de uma ampla e intensa adesão efetiva quanto à sua normação ${ }^{13}$. Para nós,

6 VERDÚ, Pablo Lucas. O sentimento constitucional: aproximação ao estudo do sentir constitucional como modelo de integração política, p. 53.

7 VERDÚ, Pablo Lucas. O sentimento constitucional: aproximação ao estudo do sentir constitucional como modelo de integração política, p. 5.

8 VERDÚ, Pablo Lucas. O sentimento constitucional: aproximação ao estudo do sentir constitucional como modelo de integração política, p. 53.

9 VERDÚ, Pablo Lucas. O sentimento constitucional: aproximação ao estudo do sentir constitucional como modelo de integração política, p. 75.

10 VERDÚ, Pablo Lucas. O sentimento constitucional: aproximação ao estudo do sentir constitucional como modelo de integração política, p. 77.

11 ABREU, Ivy de Souza. A construção do sentimento constitucional brasileiro e a legitimação das decisões judiciais. In: BUSSINGUER, Elda Coelho de Azevedo; CAMPANHA, Breno Maifrede (orgs.). Direitos humanos em sociedades complexas. Vitória: FDV Publicações, 2014, p. 42.

12 VERDÚ, Pablo Lucas. O sentimento constitucional: aproximação ao estudo do sentir constitucional como modelo de integração política, p. 80-81.

13 VERDÚ, Pablo Lucas. O sentimento constitucional: aproximação ao estudo do sentir constitucional como modelo de integração política, p. 6-7. 
com a construção do sentimento constitucional, será possibilitada, primeiro, a afetividade, surgindo a base propícia, por conseguinte, para a efetividade das normas fundamentais.

Ivy de Souza Abreu, ao analisar a importância da construção do sentimento constitucional para a legitimação das decisões judiciais no Brasil, aponta que Verdú trabalha muito com a ideia de "ter, estar e sentir-se em Constituição". Ou seja, não é somente ter Constituição. "Ter uma Constituição não significa estar nela e tampouco sentir-se vinculado a ela"14.

Se René Descartes foi o autor da frase "penso, logo existo", de onde coloca-se a razão humana no centro de nossa existência, então podemos anotar para Pablo Lucas Verdú a ideia da relevância da convivência a partir da expressão "sinto, logo convivo", de onde advém, por fim, a importância do "ter e estar em Constituição", como mencionado acima: "se a Constituição é sentida, logo existe"15.

\section{PATRIOTISMO CONSTITUCIONAL}

A ideia a respeito do patriotismo constitucional surge com maior ênfase a partir das teorizações do pensador, filósofo e sociólogo alemão Jürgen Habermas. Habermas possui uma obra multiforme, tendo se tornado uma voz importante em diversas discussões intelectuais e políticas. De fato, seus estudos são bastante vastos, servindo, inclusive, para vários campos das ciências humanas, e não somente para o Direito Constitucional, a Teoria da Constituição ou temas ligados exclusivamente ao estudo da democracia ou do constitucionalismo ${ }^{16}$.

O termo "patriotismo constitucional" (no alemão, verfassungspatriotismus) foi cunhado pelo cientista político alemão Dolf Sternberger quando da comemoração dos 30 (trinta) anos da chamada "Lei Fundamental de Bonn", a Constituição da Alemanha, de 1949. Mas é Habermas que faz uma maior elucubração sobre esse conceito a partir da década de 1980.

O debate acerca do patriotismo constitucional é difundido por Habermas para que fosse possível também refletir acerca do passado nacional-socialista, um debate e uma proposta com ares constitucionais diante das barbaridades que ocorreram na Alemanha nazista. A proposta de Habermas não é fechar os olhos para o passado, esquecer por completo a história - inclusive a recente história macabra do holocausto -, mas sim aprender com os erros do passado. O autor sustenta que é necessário refletir sobre a derrota das esperanças do passado, sobre as tradições que fracassaram, sobre nossos desenganos, e, finalmente, sobre quais caminhos não podemos seguir ${ }^{17}$. Alessandro Pinzani resgata estas palavras do pensador alemão, as quais demonstram sua preocupação em torno da superação das barbáries provocadas pelo nacional-socialismo:

14 ABREU, Ivy de Souza. A construção do sentimento constitucional brasileiro e a legitimação das decisões judiciais. In: BUSSINGUER, Elda Coelho de Azevedo; CAMPANHA, Breno Maifrede (orgs.). Direitos humanos em sociedades complexas, p. 40.

15 VERDÚ, Pablo Lucas. O sentimento constitucional: aproximação ao estudo do sentir constitucional como modelo de integração política, p. 4 e p. 72.

16 Para mais detalhes das obras de Habermas, conferir: MACHADO, Vitor Gonçalves. A busca da "verdade" para Jürgen Habermas e seus reflexos no novo Código de Processo Civil brasileiro. In: Revista Portuguesa de Filosofia, vol. 70, fasc. 4, p. 811-832, 2014.

17 CITTADINO, Gisele. Patriotismo constitucional, cultura e história. In: Direito, Estado e Sociedade, n. 31, jul./dez. 2007, p. 59. 
Para nós, na república federal alemã, patriotismo constitucional significa entre outras coisas o orgulho pelo fato de que conseguimos superar o fascismo também a longo prazo, estabelecer um ordenamento de Estado de direito e ancorá-lo em uma cultura política liberal (ainda que não completamente). Nosso patriotismo não pode negar o fato de que na Alemanha somente depois de Auschwitz a democracia conseguiu fincar raízes (...) nas motivações e nos corações dos cidadãos, pelo menos das gerações mais jovens ${ }^{18}$.

Na proposta de Habermas, em compasso com a inicial proposição de Sternberger, haveria, em síntese, a substituição de três institutos/valores presentes na tradição alemã por outros três: a) o patriotismo nacional (ou nacionalismo) deve ser substituído pelo patriotismo constitucional; b) o chamado "Estado nação" (ou Estado nacional) deve dar espaço para o "Estado Democrático de Direito"; e c) a "nação de cultura" deve ser substituída por uma "nação de cidadãos".

O ponto central do patriotismo constitucional é a ideia de que a Constituição em vigor é onde deve se cristalizar a cultura política de um país ${ }^{19}$. Com esse pensamento, Habermas propõe a sedimentação do patriotismo constitucional não somente para a Alemanha, mas também para a União Europeia (uma "futura República Federal dos Estados Europeus").

É a Constituição o elo que aproxima os cidadãos. É ela, ao configurar um conjunto de valores, direitos fundamentais e princípios universalistas (princípios de direitos humanos), e não a afinidade étnica, que deve oferecer uma base democrática e uma lealdade à Alemanha.

A seu turno, será a cidadania o elemento capaz de realizar a união e cooperação entre os indivíduos. Mais que um "mero status legal", a cidadania democrática, nas palavras de Habermas, deve desenvolver sua força de integração social e ter a capacidade de "gerar solidariedade entre estranhos" na medida em que puder ser "reconhecida e valorizada como o mecanismo efetivo pelo qual a infraestrutura legal e material das formas de vida escolhidas é assegurada"20.

Não à toa, pois é próprio dos pensamentos de Habermas, sua concepção para a formação de um Estado Democrático de Direito (em substituição ao Estado nacional) deve estar alinhada ao exercício dos direitos de participação e de comunicação, ou seja, "a identidade da nação de cidadãos não reside em características étnico-culturais comuns, porém na prática de pessoas que exercitam ativamente seus direitos democráticos de participação e de comunicação"21.

18 HABERMAS apud PINZANI, Alessandro. Habermas. Porto Alegre: Artmed, 2009, p. 172-173.

19 HABERMAS, Jürgen. A inclusão do outro: estudos de teoria política. Tradução de George Sperber e Paulo Astor Soethe. São Paulo: Edições Loyola, 2002, p. 135.

20 HABERMAS, Jürgen. O Estado-nação europeu frente aos desafios da globalização. Tradução de Antonio Sérgio Rocha. In: Novos Estudos CEBRAP, São Paulo, n. 43, nov. 1995, p. 97.

21 HABERMAS, Jürgen. Direito e democracia: entre facticidade e validade. Vol. II. 2. ed. Tradução de Flávio Beno Siebeneichler. Rio de Janeiro: Tempo Brasileiro, 2003, p. 283. 
Inclusive, já tivemos oportunidade de manifestar, ao comentar a teoria habermasiana, que apenas será possível a democracia "quando houver a capacidade de respeitar os direitos dos outros, as suas diferentes concepções políticas e buscar entendimento com iguais chances de manifestação ou de chegar ao exercício do poder"22, como igualmente assevera José Pedro Luchi²3.

Enfatizando essa identidade calcada em princípios universais do Estado Democrático de Direito, sustenta Habermas que a "identidade de um povo se forma, então, em torno de princípios contidos na sua constituição e não de elementos compartilhados como história, territórios, linguagem, costumes, religião etc." 24 .

A existência de sociedades multiculturais, tais como a Suíça e os Estados Unidos, revela que uma cultura política, construída sobre princípios constitucionais, não depende necessariamente de uma origem étnica, linguística e cultural comum a todos os cidadãos. Uma cultura política liberal forma apenas o denominador comum de um patriotismo constitucional capaz de agudizar, não somente o sentido para a variedade, como também a integridade das diferentes e coexistentes formas de vida de uma sociedade multicultural ${ }^{25}$ (itálico no original).

Gisele Cittadino ${ }^{26}$ escreve que o advento do patriotismo constitucional veio justamente para que os cidadãos, a partir de seus contextos nacionais, identifiquem no Estado Democrático de Direito o resultado de sua atuação histórica, podendo, dessa maneira, salvar a herança republicana perdida.

Portanto, com o fim de fortalecer a Constituição e sustentar que é com base nos princípios universais dispostos nela, bem como na presença da cidadania democrática e em uma "nação de cidadãos", e não da cultura ou afinidade étnica, é que se forma o núcleo do pensamento para sedimentar o patriotismo constitucional.

\section{CONSTITUCIONALISMO POPULAR}

Na parte que interessa ao fenômeno histórico (assim tratado por Kramer) do constitucionalismo popular, encontramos em solo norte-americano dois autores principais que elaboram suas premissas: Mark V. Tushnet e Larry D. Kramer. O primeiro, a partir de 1999 com a obra "Taking the Constitution away from the Courts", e o segundo principalmente com a obra "The people themselves: popular constitucionalism and judicial review", de 2004.

22 MACHADO, Vitor Gonçalves. Verdade, prova e processo: esboço de uma teoria da construção da "verdade" no processo civil brasileiro. Dissertação (Mestrado em Direito Processual). Universidade Federal do Espírito Santo, Programa de Pós-Graduação em Direito, Vitória, 2015, p. 40.

23 LUCHI, José Pedro. Tensão entre autonomia privada e pública. In: Revista de Informação Legislativa, Brasília, ano 47, n. 185, jan./mar. 2010, p. 66.

24 PINZANI, Alessandro. Habermas, p. 153.

25 HABERMAS, Jürgen. Direito e democracia: entre facticidade e validade, p. 289.

26 CITTADINO, Gisele. Pluralismo, direito e justiça distributiva: elemento da filosofia constitucional contemporânea. 2. ed. Rio de Janeiro: Lumen Juris, 2000, p. 178-179. 
Entre os conceitos ora abordados neste ensaio, o constitucionalismo popular é o fenômeno mais recente entre nós, surgindo na virada do século XX para o século XXI.

Sustenta José Ribas Vieira que foi nas décadas de 1980 e 1990, "catalisando a decepção quanto ao papel da Corte Suprema nos Estados Unidos", que autores como Mark Tushnet e Bruce Ackerman assumiram uma posição radical no sentido de buscar uma "nova legitimidade democrática para o processo constitucional norte-americano (via mecanismos referendários)". Havia, naquele momento, uma reflexão em torno de a judicial review servir como mecanismo apto a "pronunciar-se em nome da sociedade americana"27.

O solo norte-americano, dessa maneira, foi propício para formar o conceito acerca do constitucionalismo popular, sendo que a experiência de mais de 2 (dois) séculos permitiu à doutrina, segundo Lincoln Magalhães da Rocha, apontar estes elementos como os princípios do chamado "Federalismo Americano":

1. União de Estados autônomos.

2. Divisão de poderes entre a União e os Estados, cabendo àquela os poderes enumerados, e, aos segundos, os residuais ou reservados.

3. Supremacia da Constituição Federal e das leis e tratados que se fizerem em decorrência desse poder.

4. Plenitude de poderes Executivo, Legislativo e Judiciário, bem como o poder de criar impostos a todos os Estados e ao governo central.

5. A supremacia da Constituição, cujo controle é exercido através dajudicial review, especialmente pela Suprema Corte ${ }^{28}$.

Assim, o constitucionalismo popular busca como objetivo principal legitimar o povo (força da frase "We the people" - nós, o povo - para a criação e a interpretação da Constituição) como verdadeira instância promotora da interpretação constitucional. São suas premissas fundamentais: a) a ideia de reivindicar a interpretação constitucional fora dos Tribunais (estes não podem ser mais a última palavra nesta interpretação); b) a autoridade do povo para estabelecer (além de realizar a interpretação) o conteúdo da Constituição.

27 VIEIRA, José Ribas. Construindo a Teoria da Constituição no século XXI: a presença norte-americana e aspectos comparativos. In: VIEIRA, José Ribas (org.). Temas de Direito Constitucional norte-americano. Rio de Janeiro: Forense, 2002, p. 7.

28 ROCHA, Lincoln Magalhães da. A Constituição americana: dois séculos de direito comparado. Rio de Janeiro: Edições Trabalhistas, 1987, p. 17-18. 
Por certo, "We the people" ("Nós, o povo") é tomado em seu sentido abstrato29, figurando, como asseverou Michel Rosenfeld, "completamente envolvente em seu abraço aparentemente pleno tanto dos constituintes quanto de todos aqueles a quem a Constituição se aplica" ${ }^{\prime \prime}$.

Novamente na perspectiva do constitucionalismo popular, conforme elucida Kramer, "a Constituição é, afinal de contas, a 'nossa' lei, escrita por 'nós, o povo', e, como tal, tem sido historicamente uma fonte especialmente fértil de inspiração para os reformadores sociais" (tradução nossa $)^{31}$. Sua crítica, nessa linha, está mais no sentido de ir contra a supremacia que tem o Judiciário na tarefa de interpretar as normas constitucionais (monopólio do Judiciário) do que propriamente defender a eliminação total da revisão judicial (judicial review).

Mark Tushnet, por sua vez, entende que a interpretação da Constituição pelos Tribunais deveria ser erradicada. Para ele, não é dado ao Poder Judiciário invalidar atos do Legislativo e do Executivo, propriamente onde existem representantes do povo. Tushnet entende que "a revisão judicial simplesmente não seria capaz de garantir os direitos constitucionais eventualmente postos em perigo"32. De acordo com Gabriela Lima, ao analisar a teoria de Tushnet,

[...] seu argumento, então, elabora-se através da desconstrução de fundamentos específicos da teoria constitucional de matriz norte-americana, tais como a conveniência de uma Corte que traga estabilidade à interpretação constitucional ou o (entendido) mito de que a interpretação realizada pelos juízes seja de melhor qualidade que a realizada por atores políticos, especialmente pelos legisladores ${ }^{33}$.

Um pensamento de Kramer marca o que se estabelece como argumento principal do constitucionalismo popular:

29 Caso a expressão "Nós, o Povo" seja abordada em seu sentido mais concreto, verificaremos, de fato, uma contradição absoluta, inclusive denunciada por Michel Rosenfeld: "[...] Os autores da Constituição Americana de 1787, um grupo de homens brancos e proprietários, não representavam de modo algum todos aqueles que estariam sujeitos às suas prescrições constitucionais. (...) À medida em que a Constituição de 1787 omite a escravidão, não se pode dizer com justiça que a expressão "Nós, o Povo" incluía os escravos afro-americanos então vivendo nos EUA" (ROSENFELD, Michel. A identidade do sujeito constitucional. Tradução de Menelick de Carvalho Netto. Belo Horizonte: Mandamentos, 2003, p. 24-25). Também nesse sentido constataram Silvagner Andrade de Azevedo e Alexandre de Castro Coura: "[...] Os autores da Constituição norte-americana de 1787 iniciaram-na com uma frase envolvente e acolhedora: 'We the people of the United States...'. Entretanto, em breve análise é possível verificar que à época apenas alguns homens, brancos, protestantes e proprietários de terra, poderiam ser calorosamente acolhidos por essa assertiva e considerados sujeitos de direitos dentro da nova ordem política que estava se fundando" (AZEVEDO, Silvagner Andrade de; COURA, Alexandre de Castro. Identidade homossexual, inclusão e igualdade: por uma (re)construção do sujeito constitucional brasileiro adequada ao paradigma do Estado Democrático de Direito. In: FABRIZ, Daury Cezar (coor.); et al. O tempo e os direitos humanos. Rio de Janeiro: Lumen Juris, 2011, p. 867).

30 ROSENFELD, Michel. A identidade do sujeito constitucional, p. 23.

31 KRAMER, Larry D. Popular constitutionalism, Circa 2004. In: California Law Review, vol. 92, n. 4, p. 959-1012, jul. 2004, p. 981.

32 LIMA, Gabriela Carneiro de Albuquerque Basto. A tensão entre o povo e as cortes: a escolha do constitucionalismo popular. Dissertação (Mestrado em Direito). Faculdade de Direito da Universidade de São Paulo, Programa de Pós-Graduação em Direito, São Paulo, 2014, p. 17.

33 LIMA, Gabriela Carneiro de Albuquerque Basto. A tensão entre o povo e as cortes: a escolha do constitucionalismo popular, p. 54. 
O ponto, finalmente, é este: para controlar a Suprema Corte, devemos primeiro reivindicar a Constituição. Isso significa repudiar publicamente os juízes que dizem que eles, e não nós, possuímos autoridade última para dizer o que significa a Constituição. (...) Significa recusar-se a ser desviado por argumentos de que o direito constitucional é muito complexo ou difícil para os cidadãos comuns. (...) Acima de tudo, significa insistir que o Supremo Tribunal é o nosso servo e não o nosso mestre (...) O Supremo Tribunal não é a mais alta autoridade do país em direito constitucional. Nós somos ${ }^{34}$.

Assim, no pensamento de Kramer, é o povo quem deve realizar a interpretação constitucional, e não o Poder Judiciário, muitas vezes nesta tarefa representado pela Suprema Corte de um país na "palavra final" de processos judiciais.

\section{4. (IM)POSSIBILIDADES PARA NOSSO PAÍS?}

Os conceitos/fenômenos históricos ora abordados, convém pontuar, foram analisados de uma forma ainda superficial, um tanto quanto resumida, porém não deixamos de lado seus principais argumentos. São três importantes fenômenos nascidos no século $X X$, e não podemos dispensar suas análises para propiciar uma base rumo à construção de uma teoria constitucional brasileira, se for possível.

Mas será que eles podem reforçar nosso pensamento no sentido de formar uma própria noção de constitucionalismo brasileiro neste momento histórico?

Primeiro, é importante ter em conta qual é o momento atual que atravessa o país. Trata-se de um momento de ruptura com o que está posto no "poder"? É um momento de virada geracional, uma época de mudanças, ou é uma mudança de época? Vivencia-se uma fase de transição do "antigo" para o "novo"? É um momento de turbulência em que, realmente, não sabemos em que momento estamos, ou, se sabemos (ou se pelo menos temos condições de refletir sobre isso), não nos revela importante saber? Mais uma pergunta nos impõe a refletir (muito mais por conta de propostas políticas do que sérios debates do direito): é melhor uma nova Constituição ou reforçar a que já existe?

São indagações que nos trazem reflexões mais profundas, muitas vezes já carregadas de certa carga emotiva ou pré-compreensões. Contudo, faz-se necessário sim ter um momento de reflexão para esses assuntos, muito embora bandeiras políticas e debates eleitorais não sejam ambientes propícios para analisar - com o rigor científico que toda pesquisa impõe - a possibilidade de adequarmos os conceitos acima assimilados para a realidade do Brasil.

34 KRAMER apud LIMA, Gabriela Carneiro de Albuquerque Basto. A tensão entre o povo e as cortes: a escolha do constitucionalismo popular, p. 52. No original: "The point, finally, is this: to control the Supreme Court, we must first lay claim to the Constitution ourselves. That means publicly repudiating Justices who say that they, not we, possess ultimate authority to say what the Constitution means. (...) It means refusing to be deflected by arguments that constitutional law is too complex or difficult for ordinary citizens. (...) Above all, it means insisting that the Supreme Court is our servant and not our master (...) The Supreme Court is not the highest authority in the land on constitutional law. We are". 
Decerto, os conceitos trazidos à tona neste estudo têm seus pontos positivos, porém apresentam também certas deficiências. Entre as possíveis falhas, destacam-se: a) o sentimento constitucional está mais atrelado aos temas de Psicologia Social do que de Teoria da Constituição, sendo uma teoria difícil de "decolar" em certos países que não experimentaram uma "luta pela Constituição" e pela sua independência; b) o patriotismo constitucional foi exclusivamente pensado para a Alemanha e uma futura República da União Europeia, e seria ao menos estranho imaginar que a identidade de um povo é formada por fatores que não sua história, seu território e seus costumes; c) já o constitucionalismo popular, de acordo com grande parte dos seus críticos, não apresenta detalhadamente como seria a anulação de uma norma considerada inconstitucional, além de faltar outras definições.

A crítica ao conceito de patriotismo constitucional parece ser mais enfatizada no sentido de que é impossível assumir um consenso de forma automática em torno de princípios democráticos, haja vista nosso mundo apresentar-se cada vez mais multicultural ${ }^{35}$. Parece ser ingênuo imaginar que todos os cidadãos estariam ligados ("elo comum") pelo que consta na Constituição em vigor e na existência de uma "cidadania democrática", tão avançada a ponto de "gerar solidariedade entre estranhos"36.

Além disso, todos os fenômenos abordados foram construídos em conformidade com as realidades daqueles países em que os autores advêm. Sua realidade histórica, suas experiências sociais e econômicas, suas instituições jurídicas. Não foram, em nenhum momento, elaborados para servirem ao Brasil de acordo com as realidades brasileiras. Foram construídos na Espanha (sentimento constitucional), na Alemanha (patriotismo constitucional) e nos Estados Unidos da América (constitucionalismo popular), países, portanto, centrais, em oposição aos países periféricos, como o Brasil. As realidades são diferentes, e isso deve ser sopesado caso se pretenda "importar" os fenômenos de forma automática.

Por outro lado, fatores positivos há no que se abordou. A "luta pela Constituição" e o afeto/adesão interna para existir normas boas e justas para a "convivência", trazidos por Verdú em seu significado mais amplo para sentimento constitucional; a reivindicação para o povo realizar a interpretação da Constituição, argumento de Kramer e Tushnet ao elaborarem o sentido de constitucionalismo popular; e a afirmativa de Habermas, ao pensar sobre o patriotismo constitucional, de que "não podemos esquecer os erros do passado", e, muito além disso, devemos aprender com eles, sintetizam bem as ideias que se almeja desenvolver ao tentar uma introdução à teoria constitucional brasileira ou, ao menos, um sentimento de Constituição no Brasil.

Ocorre que nos esbarramos em vários percalços a fim de poder implementar esses pensamentos importados. Além das diferenças de realidades históricas entre o nascimento das Constituições e do povo que as promulgou, compreende-se que existem dois principais entraves para efetivar uma teoria constitucional brasileira: a) falta de identidade dos representantes políticos com o povo, além da fragmentação partidária; e b) ausência de educação constitucional.

35 Vide: BUNCHAFT, Maria Eugenia. Algumas críticas à ideia de patriotismo constitucional. In: Pensar, Fortaleza, v. 16, n. 1, jan./jun. 2011, p. 232.

36 HABERMAS, Jürgen. O Estado-nação europeu frente aos desafios da globalização. Tradução de Antonio Sérgio Rocha. In: Novos Estudos CEBRAP, p. 97. 


\subsection{FRAGMENTAÇÃO PARTIDÁRIA BRASILEIRA E FALTA DE IDENTIDADE DOS REPRESENTANTES POLÍTICOS COM O POVO}

De acordo com dados extraídos do sítio eletrônico do Tribunal Superior Eleitoral (TSE) ${ }^{37}$, existem 35 (trinta e cinco) partidos políticos registrados no Brasil. O número, se comparado com países como Estados Unidos, França, Inglaterra e outros mais desenvolvidos, assusta. Porém, o que mais deveria assustar é a falta de identidade dos representantes políticos escolhidos pela sociedade com os anseios desta.

Dados do TSE demonstram que muitas organizações já tentaram obter registro como partido político. Ao analisar ao menos o nome das organizações, pairam dúvidas sobre a legitimidade das mesmas em representar politicamente os valores, as preferências e os anseios da sociedade brasileira, em mira, sobretudo, aos princípios e regras estabelecidos na Constituição Federal de 1988, sem ideologias ou outras preferências que possam excluir a maioria da população.

Exemplo de uma recente organização que buscou representação como legítimo partido político foi o Partido Nacional Corinthiano, cujo registro foi indeferido em 24 de setembro de 2015. Outros partidos que tiveram seus registros indeferidos foram o Partido dos Servidores Públicos e dos Trabalhadores da Iniciativa Privada do Brasil, o Partido do Povo Brasileiro e o Partido Nacional do Consumidor. Logicamente, pelo nome dessas três últimas organizações poderia ser pensado em suas aprovações como partidos a representarem o povo. Ocorre que geralmente se verifica um discurso apenas formal dos partidos, sem efetiva busca pelos interesses da sociedade, figurando o nome apenas como uma porta de entrada, algo fajuto, que buscará atender na maior parte das vezes seus próprios interesses.

José Luiz Quadros de Magalhães faz duras críticas a essa "máquina processadora de legitimidades 'democráticas' majoritárias de decisões minoritárias". O autor afirma que "a maior parte dos partidos políticos neste início de século XXI, não guarda mais coerência político-ideológica, o que resulta em um pragmatismo sem ética de busca do poder pelo poder" ${ }^{\prime \prime 3}$. De fato, poucos são os partidos políticos atuais que guardam coerência político-ideológica, sendo que a maior parte não tem mais essa coerência.

E assim se forma essa "busca da vitória", ou busca pelo "melhor argumento". A minoria (insatisfeita) acaba cedendo à maioria, mas que também está sempre dividida. No fim das contas, esse processo "inviabiliza qualquer possibilidade de consenso, pois, desde o início, o que se busca é a vitória: do partido, do projeto de lei, do melhor argumento (?)"39.

37 Disponível em: <http://www.tse.jus.br/partidos/partidos-politicos/registrados-no-tse>. Acesso em: 20 fev. 2019.

38 MAGALHÃES, José Luiz Quadros de. O novo constitucionalismo democrático na América Latina e a superação da modernidade europeia. In: Revista Interdisciplinar de Direito, Valença/RJ, v. 10, n. 1, p. 119-132, out. 2017, p. 123.

39 MAGALHÃES, José Luiz Quadros de. O novo constitucionalismo democrático na América Latina e a superação da modernidade europeia. In: Revista Interdisciplinar de Direito, p. 124. 
Ademais, há ainda uma falsa percepção de que nosso pluralismo partidário (diversidade de partidos políticos) representa uma ideia de diversidade de ideologias, de participação política de vários grupos sociais com suas diferentes percepções e valores para somar ao ambiente político, o que se mostra um grande engano. Magalhães é pontual ao criticar o palco que temos no legislativo para deliberar projetos de lei de importantes assuntos sociais:

No parlamento, os representantes, quando discutem o projeto de lei, de reforma legal ou constitucional, argumentam a partir de seu partido político, visando à vitória de seu projeto. São sempre parciais, esta é a ideia. Será que este processo permite que, neste debate, um escute o outro? Haverá efetivamente a possibilidade de diálogo? Há uma comunicação possível? Quando a pessoa que argumenta vai para um debate com a intenção de vencer o outro, esta pessoa estará aberta para ser convencida ou todo argumento do outro será recebido para ser imediatamente desmontado? ${ }^{40}$

O ideal se distancia do real. Onde deveria haver um espaço público com debate de ideias e respeito à diversidade, temos um palco onde o debate é direcionado para vencer uma tese que defende a posição de determinado partido político.

\subsection{AUSÊNCIA DE EDUCAÇÃO CONSTITUCIONAL}

Se "uma Constituição afastada da realidade está vigente", mas "no fundo ela é ignorada pelo comum das pessoas" 41 , então é possível afirmar que ensinar princípios, valores, direitos e garantias estabelecidos na Constituição Federal sem ao menos senti-los, vivê-los, observá-los e utilizá-los não se mostrará suficiente para eclodir em um povo o sentimento de Constituição.

No prólogo à obra de Pablo Lucas Verdú, o professor Agassiz Almeida Filho relembra uma conversa que teve com o autor espanhol, momento em que Verdú asseverou a importância de garantir um ensino jurídico que compreenda "a faceta política da Constituição, sua materialidade e o papel reitor atualmente desempenhado pelos direitos fundamentais" ${ }^{\prime 2}$. No Brasil, percebemos que há um discurso formal, mas pouca materialidade há do mesmo. Assim, a nosso ver, identifica-se uma flagrante falta de ensino relativo aos preceitos básicos da Constituição da República Federativa do Brasil de 1988, educação esta que deve começar desde o ensino fundamental.

Não há no país um sentimento constitucional (Lucas Verdú) ou identidade constitucional (Michel Rosenfeld). A identificação dessa falta de identificação com a Constituição Federal, com o perdão pela redundância dos termos, é complexa. Todavia, compreende-se que um fator que muito

40 MAGALHÃES, José Luiz Quadros de. O novo constitucionalismo democrático na América Latina e a superação da modernidade europeia. In: Revista Interdisciplinar de Direito, p. 124-125.

41 VERDÚ, Pablo Lucas. O sentimento constitucional: aproximação ao estudo do sentir constitucional como modelo de integração política, p. 7.

42 ALMEIDA FILHO, Agassiz. Prólogo. In: VERDÚ, Pablo Lucas. O sentimento constitucional: aproximação ao estudo do sentir constitucional como modelo de integração política. 
contribui com a ausência de sentimento de Constituição está relacionada a outra ausência sentida no Brasil: a ausência de uma educação constitucional.

\section{A IMPORTÂNCIA DA EDUCAÇÃO CONSTITUCIONAL (PARA FLORESCER O SENTIMENTO DE CONSTITUIÇÃO)}

Há no país pelo menos uma ideia de que a educação é uma importante política pública para o desenvolvimento socioeconômico, devendo ser direito de todos e dever do Estado, assim como está expresso na Constituição. A educação está positivada na CF/1988 como direito social (art. 6²), e seus princípios foram arrolados no art. 206, comando constitucional que estabeleceu a "garantia do padrão de qualidade" como um dos princípios pelos quais o ensino deve ser ministrado. Outra norma constitucional relevante é a que estabelece como direito público subjetivo o acesso ao ensino obrigatório e gratuito, conforme rege o art. 208, $\S 1^{\circ}$, da Carga Magna ${ }^{43}$.

Nesse sentido, um importante passo para "sentirmos" a Constituição, com uma adesão interna e espontânea da pessoa às normas e instituições fundamentais do país, é colocar em prática o ensino em relação aos princípios, aos direitos, aos deveres e às garantias básicas presentes na Carta Magna, e que essa educação seja iniciada ainda nos primeiros anos da pessoa, ou, especificando melhor, que seja iniciado no ensino fundamental - política esta que ainda não temos.

Recentemente, o Ministro do Supremo Tribunal Federal (STF) Luís Roberto Barroso chamou a atenção para a importância da educação no país, a qual, de fato, tem sido relegada. Barroso entende que deve existir um "pacto suprapartidário pela educação", o qual, conjuntamente com outros pactos e medidas, seria uma medida para unir os brasileiros:

Quando da sucessão da presidente Dilma Roussef pelo presidente Michel Temer, a grande discussão entre os formadores de opinião era quem seria o ministro da Fazenda, quem seria o presidente do Banco Central, quem seria o presidente do BNDES. A educação, que todos dizem que é prioridade, entrou no racha geral. Precisamos dos melhores nomes, dos projetos que deram certo pelo mundo afora e precisamos blindar a educação do varejo da política. Tivemos cinco ministros da Educação em quatro anos e meio. Não há política pública que resista a essa descontinuidade.

Ao contrário de outras áreas, em tema de educação já temos alguns diagnósticos precisos: (i) não alfabetização da criança na idade certa; (ii) evasão escolar no ensino médio; e (iii) déficit de aprendizado, isto é, os jovens terminam o ensino fundamental e o ensino médio sem terem aprendido o essencial. E há uma solução que tem sido chancelada por pesquisas recentes: a ênfase na educação infantil de zero a três anos, fase em que o cérebro da criança é uma esponja que absorve todas as informações que lhe são passadas. Esta é a hora de dar nutrição, afeto, respeito, valores e capacidades cognitivas ${ }^{44}$.

43 BRASIL. Constituição da República Federativa do Brasil. Brasília, 1988. Disponível em: <http://www.planalto. gov.br/ccivil_03/constituicao/constituicao.htm>. Acesso em: 31 jul. 2020.

44 BARROSO, Luís Roberto. Três pactos necessários que são capazes de unir os brasileiros. In: Revista Consultor Jurídico, São Paulo, 29 out. 2018. 
Já quanto à análise de legislações ou propostas legislativas que pretendem incluir o ensino da Constituição nas escolas, foi possível verificar a existência do Projeto de Lei do Senado (PLS) de $n^{\circ} 70$, de 2015, de iniciativa do Senador Romário. De acordo com a justificativa do projeto, seu objetivo é expandir a noção cívica aos estudantes do país, "ensinando-lhes sobre seus direitos constitucionais, como cidadão e futuro eleitor, e, em contrapartida, aprenderem sobre seus deveres"45.

Algumas emendas ao PLS 70/2015 foram incluídas em 2017, como a obrigatoriedade do curso de Primeiros Socorros para o ensino fundamental e médio. Sua tramitação já se encontra na Câmara dos Deputados, com a nomenclatura PL n 3380/2015, porém em 2018 não teve qualquer movimentação.

Na Câmara dos Deputados, a proposição original foi modificada e está atualmente assim redigida, pretendendo incluir estas modificações nos artigos 27 e 32 da Lei n 9.394/1996 (Lei de Diretrizes e Bases da Educação Nacional) ${ }^{46 .}$

\section{Capítulo II: Da Educação Básica}

Seção I: Disposições Gerais

Art. 27. Os conteúdos curriculares da educação básica observarão, ainda, as seguintes diretrizes:

I - difusão de valores fundamentais ao interesse social e aos direitos e deveres dos cidadãos e de respeito ao bem comum e à ordem democrática, com $a$ introdução do estudo da Constituição Federal;

\section{(...)}

Art. 32. (...)

II - a compreensão do ambiente natural e social, do sistema político, do exercício da cidadania, da tecnologia, das artes e dos valores éticos e cívicos em que se fundamenta a sociedade;

\section{(...) (destacou-se)}

Dessa forma, é possível perceber que a proposta pretende incluir a "introdução do estudo da Constituição Federal". Todavia, ainda não se sabe ao certo como se efetivará essa disposição, isto é, se o conteúdo será "diluído" em outras matérias ou se haverá uma disciplina específica para esse fim.

45 Disponível em: <https://www25.senado.leg.br/web/atividade/materias/-/materia/119869>. Acesso em: 26 fev. 2019.

46 Disponível em: <https://www.camara.leg.br/proposicoesWeb/fichadetramitacao?idProposicao=2024319>. Acesso em: 26 fev. 2019. 
Veja-se, até o momento, que a educação constitucional é discutida no plano ideal das propostas. Mas há alguma medida prática, algum projeto em curso que já pensou em efetivar essa proposta?

Em uma rápida análise em projetos brasileiros sobre o tema, verifica-se que há em curso o intitulado "Projeto Constituição na Escola", o qual se trata de uma boa iniciativa, porém, a nosso ver, ainda não resolve o problema. Parece-nos que o Projeto Constituição na Escola tende a ser mais um projeto comercial com intenção de sua internacionalização do que realmente um programa eficiente e social. Mas o projeto, conforme menciona seu próprio fundador, ainda está no início, sabendo, assim, que todo início é mais tormentoso, com erros e acertos (às vezes muito mais erros do que acertos).

De acordo com o fundador Felipe Costa Rodrigues Neves, há a preocupação em se transmitir noções básicas sobre "Constituição Federal, política e civilidade, sempre sem qualquer influência ideológica ou de partido político, dando ao aluno a 'informação pura' para que ele" possa "desenvolver seu pensamento crítico, seja ela (sic) qual for" 47 (destacou-se). No entanto, é ao menos duvidoso querer expor um projeto em que haja a pretensão de levar "informações puras" ao público-alvo, que no caso são as crianças e adolescentes das escolas públicas brasileiras. Isto porque já se sabe que não existem programas ou ideias puras, com neutralidade. A própria pretensão de "pureza" já se configura uma ideologia, que pode representar uma ideologia neoliberal, "de direita", conservadora, ou, ainda, pretensiosa em atender a interesses empresariais e/ou políticos.

Dentro dessa ótica, é válido problematizar a atual situação caótica em que atravessa a educação no país. Ou seja, mesmo dentro de uma área que não recebe investimentos como deveria e possui profissionais mal valorizados, como pretender e insistir em inserir o conteúdo da "introdução à Constituição Federal" (mesma expressão que consta no PL n 3380/2015, recebido em 21 de outubro de 2015 pela Câmara dos Deputados) para crianças e adolescentes?

Primeiro, sabe-se que existem professores que mal planejam suas aulas (ou que têm dificuldades para planejar as aulas e o período letivo da disciplina); que não transmitem conteúdo satisfatório e com visões amplas e diferentes sobre um assunto; que não abordam de forma ética e respeitosa determinada matéria, polêmica ou não; que se dirigem ao aluno de forma irônica, muitas vezes ridicularizando-o; que usam de provas como instrumento de punição de alunos ou turmas; que exigem rígida disciplina dentro de sala de aula, desencorajando participações dos alunos; e que adotam outras práticas negativas, as quais foram também mencionadas por Maria Eugênio Castanho ${ }^{48}$. Todavia, o caminho não pode ser nesse tom, de forma que é preciso, ao mesmo tempo em que pretendemos valorizar aqueles conceitos trabalhados nos capítulos anteriores - em especial o sentimento constitucional -, saber que a educação no país é (ou pelo menos deve ser) também valorizada em todos os seus ângulos. Conforme explicam Selma Garrido Pimenta e Léa Anastasiou, "aprender não é um processo que se efetive sem rotinas ou ocorra de forma espontânea ou mágica".

47 Vide: NEVES, Felipe Costa Rodrigues. Projeto Constituição na Escola: a história e a necessidade do ensino. In: Migalhas, 23 mar. 2018.

48 CASTANHO, Maria Eugênia L. M. A escola brasileira e o desafio de professores marcantes. In: Evidência, Araxá, v. 12, n. 12, 2016, p. 22. 
Exige-se, segundo as autoras, "a escolha e execução de uma metodologia adequada aos objetivos e conteúdos do objeto de ensino e aos alunos"49.

Não se pode enxergar a educação, como nos parece transparecer o citado "Projeto Constituição na Escola" - ou o que pode ocorrer também com o PL 3380/2015 caso não bem aprofundado e problematizado -, como um produto que está pronto, onde haverá uma transmissão (no caso em comento, transmissão pura das normas que estão na Constituição Federal de 1988) sem rupturas, sem retoques ${ }^{50}$. É importante enfatizar que devemos superar/romper com a "educação bancária" de que Paulo Freire critica, "para a qual a educação é o ato de depositar, de transferir, de transmitir valores e conhecimentos", ou seja, uma educação em que nela:

O educador é o que educa; os educandos, os que são educados;

O educador é o que sabe; os educandos, os que não sabem;

O educador é o que pensa; os educandos, os pensados;

O educador é o que diz a palavra; os educandos, os que escutam docilmente;

O educador é o que disciplina; os educandos, os disciplinados;

O educador é o que opta e prescreve sua opção; os educandos, os que seguem a prescrição;

O educador é o que atua; os educandos, os que têm a ilusão de que atuam, na atuação do educador;

O educador escolhe o conteúdo programático; os educandos, jamais ouvidos nesta escolha, se acomodam a ele;

O educador identifica a autoridade do saber com sua autoridade funcional, que opõe antagonicamente à liberdade dos educandos; estes devem adaptar-se às determinações daquele;

O educador, finalmente, é o sujeito do processo; os educandos, meros objetos ${ }^{51}$.

Portanto, com o pensamento de que devemos valorizar a educação e que as noções de lógica e cognição responsáveis pelo aprendizado futuro têm seu primeiro impulso na educação infantil52, pretende-se dar início a uma "teoria da educação constitucional" com o fim de, a médio e longo prazo, florescer em solo brasileiro o sentimento de Constituição.

49 PIMENTA, Selma Garrido; ANASTASIOU, Léa das Graças Camargos. Docência no ensino superior. São Paulo: Cortez, 2002, p. 211.

50 Vide: FRANCISCHETTO, Gilsilene Passon Picoretti. Em busca de novos saberes: uma aproximação entre o ensino jurídico e a pedagogia. In: Curitiba: CRV, 2010, p. 16.

51 FREIRE, Paulo. Pedagogia do oprimido. 17. ed. Rio de Janeiro: Paz e Terra, 1987, p. 59.

52 Vide: FOLHA DE SÃO PAULO (Estúdio Folha). Aprendizado começa na primeira infância. São Paulo, 01 nov. 2017. Disponível em: <http://estudio.folha.uol.com.br/coc/2017/11/1932130-aprendizado-comeca-na-primeirainfancia.shtml>. Acesso em: 27 fev. 2019. 
Decerto, não se deve propor aos estudantes da educação básica o ensino de institutos como controle judicial de constitucionalidade das leis, fundamentação das decisões judiciais, sistema de precedentes judiciais, formação das súmulas vinculantes, rito de aprovação de uma emenda constitucional etc., mas sim temas básicos que, dentre outros, estão relacionados ao exercício da cidadania e aos direitos e garantias fundamentais. Poderíamos, assim, imaginar a introdução do estudo da Constituição Federal (mesmo nome que consta no PL n 3380/2015) aos alunos da educação básica com pelo menos o seguinte conteúdo: a) História da Constituição no Brasil; b) Princípios fundamentais estabelecidos na Constituição; c) Direitos e garantias fundamentais, inclusive deveres fundamentais expressos na CF/1988; d) Noções sobre direitos políticos; e) Noções de organização do Estado (União, Estados, Municípios e Distrito Federal); f) Funções dos Tribunais Superiores, em especial o Supremo Tribunal Federal (STF); g) Noções básicas sobre tributos e atividade econômica; h) Noções básicas sobre saúde, previdência e assistência social; i) Noções sobre meio ambiente; j) Noções básicas sobre o que a CF/1988 dispõe acerca de cultura, educação, ciência, família, idoso e índios ${ }^{53}$.

O conteúdo - é necessário ressaltar - deve ser ensinado com os olhos de um aluno do ensino fundamental ou médio, ou seja, de uma forma didática e empática, sem vícios próprios de certas profissões jurídicas (como o abuso de expressões em latim ou palavras mais difíceis, além da falta de preparação das aulas e ausência de metodologia de ensino). Não pode ser uma transmissão de conteúdo mecânica, em uma típica aula expositiva dialogada (dialogada apenas na teoria, frisa-se), como a "educação bancária" que Paulo Freire critica. Deve envolver criatividade e trato cuidadoso com os alunos, principalmente.

A nosso ver, não deve ser mais uma disciplina a "entupir" a carga horária das crianças e dos adolescentes, muitos dos quais já se encontram engolidos por compromissos fúteis. Deve haver real comprometimento com o estudo da Constituição Federal, de forma que, seja ou não uma disciplina específica na grade curricular, possa ser ministrada por especialistas que detém cuidado especial com esse público-alvo, sem falhas didáticas que boa parte dos profissionais do ensino jurídico possui.

\section{CONSIDERAÇÕES FINAIS}

As noções de patriotismo constitucional e constitucionalismo popular não são concretamente possíveis para o Brasil. Suas noções nasceram em outros contextos, em realidades muito diferentes que as vivenciadas em nosso país, como foi possível verificar ao longo deste artigo. De fato, os fenômenos abordados foram construídos dentro de realidades históricas, econômicas, políticas, jurídicas e culturais daqueles países que os autores das ideias desses fenômenos advêm. Ou seja, vieram da Espanha (sentimento constitucional), da Alemanha (patriotismo constitucional) e dos

53 Também com um pensamento próximo dessa ideia: FRANÇA, Suelen Cardoso. Direito Constitucional como disciplina obrigatória nas escolas brasileiras de educação básica: análise do projeto de lei $n^{\circ} 70 / 2015$. In: Jus Navigandi, nov. 2017. Disponível em: <https://jus.com.br/artigos/62094/direito-constitucional-como-disciplinaobrigatoria-nas-escolas-brasileiras-de-educacao-basica-analise-do-projeto-de-lei-n-70-2015>. Acesso em: 31 jul. 2020. 
Novos Estudos Jurídicos

Estados Unidos da América (constitucionalismo popular). É difícil, além de ser por vezes perigoso e não recomendável, querer automaticamente importar ideais estrangeiros que foram originados (e se acostumaram com isso) em outros contextos e realidades distintas das que os brasileiros enfrentam e já passaram. Mas a noção de sentimento constitucional, talvez, seja possível no Brasil.

Para tanto, uma dúvida remanesce: é necessária uma nova Constituição em nosso país? Esse foi um vivo debate no ano de 2018, quando se completou 30 (trinta) anos de sua publicação. Contudo, o problema da Constituição não é da Constituição. O problema da Constituição é nosso.

Até onde é possível observar, não há espaços na educação pública ou privada no país que ofereçam acesso aos direitos, às garantias, aos princípios, aos deveres e às políticas positivadas em 1988 pelo legislador constituinte. Em outras palavras, não se ensina Constituição nas escolas brasileiras. E se ainda não há sentimento constitucional no Brasil, uma das respostas que pode justificar essa carência é a falta, desde o ensino fundamental, de uma educação propícia sobre a própria Constituição da República Federativa de 1988.

Entretanto, essa proposta não virá à tona de forma espontânea ou mágica. Diz-se que um sentimento de Constituição apenas se presenciou em países que lutaram (sangrentamente) pela sua Constituição. É preciso um "derramamento" de sangue para que possamos sentir a CF/88 e os institutos fundamentais do país? É preciso lutar violentamente para fazer valer os direitos e as garantias fundamentais expressos no texto constitucional? Acreditamos que não. O que nos falta é educação sobre a Constituição brasileira. E desde o início da formação do indivíduo. Sendo assim, talvez seja possível, futuramente, vivenciarmos um sentimento constitucional.

\section{REFERÊNCIAS DAS FONTES CITADAS}

ABREU, Ivy de Souza. A construção do sentimento constitucional brasileiro e a legitimação das decisões judiciais. In: BUSSINGUER, Elda Coelho de Azevedo; CAMPANHA, Breno Maifrede (orgs.). Direitos humanos em sociedades complexas. Vitória: FDV Publicações, 2014, p. 36-51.

ALMEIDA FILHO, Agassiz. Prólogo. In: VERDÚ, Pablo Lucas. O sentimento constitucional: aproximação ao estudo do sentir constitucional como modelo de integração política. Tradução e prefácio de Agassiz Almeida Filho. Rio de Janeiro: Forense, 2004.

AZEVEDO, Silvagner Andrade de; COURA, Alexandre de Castro. Identidade homossexual, inclusão e igualdade: por uma (re)construção do sujeito constitucional brasileiro adequada ao paradigma do Estado Democrático de Direito. In: FABRIZ, Daury Cezar (coor.); et al. O tempo e os direitos humanos. Rio de Janeiro: Lumen Juris, 2011, p. 867-880.

BARROSO, Luís Roberto. Três pactos necessários que são capazes de unir os brasileiros. In: Revista Consultor Jurídico, São Paulo, 29 out. 2018. Disponível em: <https://www.conjur.com.br/2018-out-29/barroso-trespactos-sao-capazes-unir-todos-brasileiros>. Acesso em: 30 out. 2018.

BRASIL. Constituição da República Federativa do Brasil. Brasília, 1988. Disponível em: <http://www.planalto. gov.br/ccivil_03/constituicao/constituicao.htm>. Acesso em: 31 jul. 2020. 
BRASIL. Lei n 9.394, de 20 de dezembro de 1996. Brasília, 1996. Disponível em: < http://www.planalto.gov.br/ ccivil_03/leis/l9394.htm>. Acesso em: 31 jul. 2020.

BUNCHAFT, Maria Eugenia. Algumas críticas à ideia de patriotismo constitucional. In: Pensar, Fortaleza, v. 16, n. 1, p. 224-245, jan./jun. 2011.

CASTANHO, Maria Eugênia L. M. A escola brasileira e o desafio de professores marcantes. In: Evidência, Araxá, v. 12, n. 12, p. 15-25, 2016.

CITTADINO, Gisele. Patriotismo constitucional, cultura e história. In: Direito, Estado e Sociedade, n. 31, p. 5868, jul./dez. 2007.

CITTADINO, Gisele. Pluralismo, direito e justiça distributiva: elemento da filosofia constitucional contemporânea. 2. ed. Rio de Janeiro: Lumen Juris, 2000.

FOLHA DE SÃO PAULO (Estúdio Folha). Aprendizado começa na primeira infância. São Paulo, 01 nov. 2017. Disponível em: <http://estudio.folha.uol.com.br/coc/2017/11/1932130-aprendizado-comeca-na-primeirainfancia.shtml>. Acesso em: 27 fev. 2019.

FRANÇA, Suelen Cardoso. Direito Constitucional como disciplina obrigatória nas escolas brasileiras de educação básica: análise do projeto de lei $n^{\circ}$ 70/2015. In: Jus Navigandi, nov. 2017. Disponível em: <https://jus.com.br/ artigos/62094/direito-constitucional-como-disciplina-obrigatoria-nas-escolas-brasileiras-de-educacao-basica-analise-doprojeto-de-lei-n-70-2015>. Acesso em: 31 jul. 2020.

FRANCISCHETTO, Gilsilene Passon Picoretti. Em busca de novos saberes: uma aproximação entre o ensino jurídico e a pedagogia. In: 2010, p. 13-52. (org.) Ensino jurídico e pedagogia: em busca de novos saberes. Curitiba: CRV,

FREIRE, Paulo. Pedagogia do oprimido. 17. ed. Rio de Janeiro: Paz e Terra, 1987.

HABERMAS, Jürgen. A inclusão do outro: estudos de teoria política. Tradução de George Sperber e Paulo Astor Soethe. São Paulo: Edições Loyola, 2002.

HABERMAS, Jürgen. Direito e democracia: entre facticidade e validade. Vol. II. 2. ed. Tradução de Flávio Beno Siebeneichler. Rio de Janeiro: Tempo Brasileiro, 2003.

HABERMAS, Jürgen. O Estado-nação europeu frente aos desafios da globalização. Tradução de Antonio Sérgio Rocha. In: Novos Estudos CEBRAP, São Paulo, n. 43, p. 87-101, nov. 1995.

KRAMER, Larry D. Popular constitutionalism, Circa 2004. In: California Law Review, vol. 92, n. 4, p. 959-1012, jul. 2004. Disponivel em: <https://scholarship.law.berkeley.edu/californialawreview/vol92/iss4/1/>. Acesso em: 30 out. 2018.

LIMA, Gabriela Carneiro de Albuquerque Basto. A tensão entre o povo e as cortes: a escolha do constitucionalismo popular. Dissertação (Mestrado em Direito). Faculdade de Direito da Universidade de São Paulo, Programa de Pós-Graduação em Direito, São Paulo, 2014.

LUCHI, José Pedro. Tensão entre autonomia privada e pública. In: Revista de Informação Legislativa, Brasília, ano 47, n. 185, p. 57-69, jan./mar. 2010.

MACHADO, Vitor Gonçalves. A busca da "verdade" para Jürgen Habermas e seus reflexos no novo Código de Processo Civil brasileiro. In: Revista Portuguesa de Filosofia, vol. 70, fasc. 4, p. 811-832, 2014.

MACHADO, Vitor Gonçalves. Verdade, prova e processo: esboço de uma teoria da construção da "verdade" no processo civil brasileiro. Dissertação (Mestrado em Direito Processual). Universidade Federal do Espírito Santo, Programa de Pós-Graduação em Direito, Vitória, 2015. 
MADALENA, Luis Henrique Braga; BEBER, Rafael Contreiras Costa. O sentimento constitucional como meio propiciador do desvelamento da Constituição (acontecer constitucional): de como o artigo 334, I, do CPC não chancela a discricionariedade judicial. In: Revista da Faculdade de Direito do Sul de Minas, Pouso Alegre, v. 29, n., p. 123-154, jan./jun. 2013.

MAGALHÃES, José Luiz Quadros de. O novo constitucionalismo democrático na América Latina e a superação da modernidade europeia. In: Revista Interdisciplinar de Direito, Valença/RJ, v. 10, n. 1, p. 119-132, out. 2017. Disponível em: <http://revistas.faa.edu.br/index.php/FDV/article/view/193>. Acesso em: 05 nov. 2018.

NEVES, Felipe Costa Rodrigues. Projeto Constituição na Escola: a história e a necessidade do ensino. In: Migalhas, 23 mar. 2018. Disponível em: <https://www.migalhas.com.br/ConstituicaonaEscola/123,MI276859,81042-Proj eto +Constituicao+na+Escola+A+historia+e+a+necessidade+do+ensino >. Acesso em: 20 fev. 2019.

PIMENTA, Selma Garrido; ANASTASIOU, Léa das Graças Camargos. Docência no ensino superior. São Paulo: Cortez, 2002.

PINZANI, Alessandro. Habermas. Porto Alegre: Artmed, 2009.

ROCHA, Lincoln Magalhães da. A Constituição americana: dois séculos de direito comparado. Rio de Janeiro: Edições Trabalhistas, 1987.

ROSENFELD, Michel. A identidade do sujeito constitucional. Tradução de Menelick de Carvalho Netto. Belo Horizonte: Mandamentos, 2003.

VERDÚ, Pablo Lucas. O sentimento constitucional: aproximação ao estudo do sentir constitucional como modelo de integração política. Tradução e prefácio de Agassiz Almeida Filho. Rio de Janeiro: Forense, 2004.

VIEIRA, José Ribas. Construindo a Teoria da Constituição no século XXI: a presença norte-americana e aspectos comparativos. In: VIEIRA, José Ribas (org.). Temas de Direito Constitucional norte-americano. Rio de Janeiro: Forense, 2002, p. 1-9.

Recebido em:

Aprovado em: 